\title{
Carbocisteine inhibits rhinovirus infection in human tracheal epithelial cells
}

\author{
H. Yasuda*, M. Yamaya*, T. Sasaki*, D. Inoue*, K. Nakayama*, M. Yamada*, \\ M. Asada*, M. Yoshida*, T. Suzuki*, H. Nishimura* and H. Sasaki*
}

ABSTRACT: The aim of the study was to examine the effects of a mucolytic drug, carbocisteine, on rhinovirus (RV) infection in the airways.

Human tracheal epithelial cells were infected with a major-group RV, RV14.

RV14 infection increased virus titres and the cytokine content of supernatants. Carbocisteine reduced supernatant virus titres, the amount of RV14 RNA in cells, cell susceptibility to RV infection and supernatant cytokine concentrations, including interleukin (IL)-6 and IL-8, after RV14 infection. Carbocisteine reduced the expression of mRNA encoding intercellular adhesion molecule (ICAM)-1, the receptor for the major group of RVs. It also reduced the supernatant concentration of a soluble form of ICAM-1, the number and fluorescence intensity of acidic endosomes in the cells before RV infection, and nuclear factor- $\mathrm{B}$ activation by RV14. Carbocisteine also reduced the supernatant virus titres of the minor group RV, RV2, although carbocisteine did not reduce the expression of mRNA encoding a low density lipoprotein receptor, the receptor for RV2.

These results suggest that carbocisteine inhibits rhinovirus 2 infection by blocking rhinovirus RNA entry into the endosomes, and inhibits rhinovirus 14 infection by the same mechanism as well as by reducing intercellular adhesion molecule-1 levels. Carbocisteine may modulate airway inflammation by reducing the production of cytokines in rhinovirus infection.

KEYWORDS: Common cold, endosome, intercellular adhesion molecule, mucolytic drug, rhinovirus

$\mathbf{R}$ hinoviruses (RVs) are the major cause of the common cold and the most common acute infectious illnesses in humans [1]. RVs are also associated with acute exacerbations of bronchial asthma [2] and chronic obstructive pulmonary disease (COPD) [3]. Several mechanisms of action have been proposed, and the manifestations of RV-induced pathogenesis are thought to be the result of virus-induced mediators of inflammation [3-5].

$R V$ infection induces the production of cytokines, including interleukin (IL)-1, IL-6 and IL-8 [5-7]. These cytokines exert pro-inflammatory effects [8] and may be related to the pathogenesis of RV infections. Mucolytic or mucoactive drugs, such as L-carbocisteine or carbocysteine lysine salt monohydrate (SCMC-Lys), are used clinically in patients with COPD and bronchial asthma in various countries, including Japan and Italy [9]. SCMC-Lys reduces the concentration of IL-6 in the breath condensate of acute COPD patients [10], suggesting anti-inflammatory effects of SCMC-Lys in COPD. SCMC-Lys [11] and Scarboxymethylcysteine (SCMC) [12] also reduce the number of inflammatory cells in airways after exposure to cigarette smoke or sulphur dioxide in rats, and inhibit neutrophil activation [13]. These findings are suggestive of anti-inflammatory effects of mucolytic drugs, including carbocysteine. However, the effects of carbocisteine on cytokine production in airway epithelial cells with RV infections have not been studied.

Recent reports have revealed that the major group of RVs enter the cytoplasm of infected cells after binding to their receptor intercellular adhesion molecule (ICAM)-1 [14, 15]. The entry of the RNA of a major group RV, RV14, into the cytoplasm of infected cells is thought to be mediated by destabilisation from receptor binding and endosomal acidification [15]. Macrolide antibiotics, such as bafilomycin [16, 17] and erythromycin [7], inhibit infection by the major group of RVs via a reduction in ICAM-1 expression $[7,17]$ and an increase in endosomal $\mathrm{pH}[7$, 16]. Glucocorticoid also inhibits RV14 infection via reduction of ICAM-1 expression [18]. Airway inflammation induced by viral infections, including RV infections, is associated with

\section{AFFILIATIONS}

*Dept of Geriatric and Respiratory Medicine, Tohoku University School of Medicine, and

\#Virus Research Centre, Clinical Research Division, Sendai National Hospital, Sendai, Japan.

\section{CORRESPONDENCE}

H. Yasuda

Dept of Geriatric and Respiratory Medicine

Tohoku University School of Medicine

1-Seiryo-machi

Aoba-ku

Sendai 980-8574

Japan

Fax: 81227177186

E-mail: yasuda@

geriat.med.tohoku.ac.jp

Received:

May 182005

Accepted after revision:

February 172006

\section{SUPPORT STATEMENT}

This study was supported by GrantsIn-Aid for Scientific Research from the Ministry of Education, Science and Culture of the Japanese government (Tokyo, Japan) to M. Yamaya (16590732) and $H$. Yasuda (17790524), a grant from Japanese Foundation for Aging and Health (Aichi, Japan) to K. Nakayama, and Health and Labour Sciences Research Grants for Research on Measures for Intractable Diseases from the Ministry of Health, Labour and Welfare of the Japanese government (Tokyo, Japan) to M. Yamaya (17243601). 
exacerbations of COPD [3, 4]. SCMC-Lys prevents acute exacerbations of COPD [9]. However, the mechanisms, other than anti-inflammatory effects in COPD [10], are still uncertain. Conversely, N-acetylcysteine, another mucolytic drug, reduces the expression of ICAM-1 in the lung [19]. Therefore, it is conceivable that carbocisteine may modulate the function of airway epithelial cells, including expression of ICAM-1, and may inhibit RV infection. However, the effects of carbocisteine on RV infection have not been studied.

Therefore, the effects of carbocisteine on RV infection in human airway epithelial cells were studied. The effects of carbocisteine on the production of ICAM-1 and cytokines, and on endosomal $\mathrm{pH}$, were also examined in order to clarify the mechanisms responsible for the inhibition of RV infection.

\section{MATERIALS AND METHODS \\ Patient characteristics}

Tracheae for cell culture were obtained after death from 25 patients (mean age $64 \pm 2$ yrs; 10 female, 15 male) under a protocol approved by the Ethics Committee of Tokohu University School of Medicine. The causes of death included acute myocardial infarction $(n=8)$, malignant tumour other than lung cancer $(n=8)$, cerebral bleeding $(n=3)$, rupture of an aortic aneurysm $(n=2)$, renal failure $(n=2)$, congestive heart failure $(n=1)$ and malignant lymphoma $(n=1)$.

\section{Human tracheal epithelial cell culture}

Isolation and culture of the human tracheal surface epithelial cells were performed as described previously [7, 17].

\section{Viral stocks and detection and titration of viruses}

Stocks of a minor group RV, RV2, and a major group RV, RV14, were prepared from patients with common colds by infecting human embryonic fibroblast cells as described previously [7, 17]. Detection and titration of RVs were performed by observing the cytopathic effects of the viruses on the fibroblast cells using previously described methods [7, 17], and the amount of specimen required to infect $50 \%$ of the fibroblast cells $(50 \%$ tissue culture infective dose (TCID50)) was determined.

\section{Detection and quantification of rhinovirus RNA}

Detection and quantification of RV14 RNA in human tracheal epithelial cells were performed by RT-PCR as previously described [7, 17]. In addition, in order to quantify RV14 RNA and reduced glyceraldehye-3-phosphate dehydrogenase mRNA expression in the cells after RV infection, real-time quantitative RT-PCR, using the Taqman technique (Roche Molecular Diagnostic Systems, Foster, CA, USA), was performed as previously described [17, 20-22]. The program PrimerExpress (Applied Biosystems, Foster, CA, USA) was used to design the probe and primers based on guidelines for the optimal performance of the PCR $[7,17]$.

\section{Measurement of lactate dehydrogenase concentration}

The amount of lactate dehydrogenase (LDH) in the culture supernatants was measured using the method described by AMADOR et al. [23].

\section{Effects of carbocisteine on viral infection}

In order to examine the effects of carbocisteine on viral titres and the cytokine content of supernatants, and the mRNA expression of ICAM-1, the receptor for the major group of RVs [14], and the low-density lipoprotein (LDL) receptor, the receptor for the minor group of RVs [24], and RV14 RNA expression, the cells were treated with $10 \mu \mathrm{M}$ carbocisteine or vehicle (PBS) beginning 3 days before RV infection and continuing until the end of the experiments [17]. This timeframe was chosen because the maximum concentrations of SCMC in the serum become $>10 \mu \mathrm{M}$ after oral ingestion of $1,500 \mathrm{mg}$ SCMC [25]. The cells were then exposed to RV2 $\left(1 \times 10^{5} \mathrm{TCID} 50 \cdot \mathrm{mL}^{-1}\right)$, RV14 $\left(1 \times 10^{5} \mathrm{TCID} 50 \cdot \mathrm{mL}^{-1}\right)$ or vehicle (Eagle's minimum essential medium) for $60 \mathrm{~min}$ and cultured at $33^{\circ} \mathrm{C}$ with rolling, as described previously $[7,17]$.

\section{Study protocol}

In order to measure the time course of viral release during the first $24 \mathrm{~h}$, four separate cultures from the same trachea were used, and the results calculated from seven different tracheae. The culture supernatants were collected at either 1, 6, 12 or $24 \mathrm{~h}$ after RV14 infection. In order to measure viral titre during the 24-48 h after RV infection, supernatants were also collected at $48 \mathrm{~h}$ after RV infection. The viral content of the supernatant was expressed in TCID50 units per millilitre.

In order to examine the concentration-dependent effects of carbocisteine on RV infection, cells were treated with carbocisteine at concentrations ranging $0.01-30 \mu \mathrm{M}$.

The effects of carbocisteine on susceptibility to RV14 infection were evaluated as previously described $[6,7]$, using epithelial cells pre-treated with carbocisteine $(10 \mu \mathrm{M}, 3$ days) or vehicle (PBS, 3 days). The cells were then exposed to serial 10-fold dilutions of RV14 or vehicle (Eagle's minimum essential medium) for $1 \mathrm{~h}$ at $33^{\circ} \mathrm{C}$. The presence of $\mathrm{RV} 14$ in the supernatants collected 1-3 days after infection was determined using the human embryonic fibroblast cell assay, described above, in order to assess whether infection occurred at each RV dose used.

\section{Measurement of intercellular adhesion molecule-1 and low- density lipoprotein receptor expression}

The mRNAs of ICAM-1 and LDL receptor were examined using real-time RT-PCR analysis as previously described [7]. In addition, concentrations of a soluble form of ICAM-1 (sICAM1) were measured in culture supernatants using an enzyme immunoassay.

\section{Effects of carbocisteine on cytokine production}

IL-1 $\beta$, IL-6, IL-8 and tumour necrosis factor (TNF)- $\alpha$ were measured in culture supernatants using specific ELISAs [7].

Measurement of changes in acidic endosome distribution The fluorescence intensity of acidic endosomes in the cells was measured, as previously described, using a dye, LysoSensor DND-189 (Molecular Probes, Eugene, OR, USA) [7, 17], from $100 \mathrm{~s}$ before to $300 \mathrm{~s}$ after the treatment with carbocisteine $(10 \mu \mathrm{M})$ or vehicle (PBS).

\section{Isolation of nuclear extracts and electrophoretic mobility shift assays}

The extraction of nuclei and electrophoretic mobility shift assays were performed as previously described [7]. 


\section{Statistical analysis}

Results are expressed as mean \pm SEM. Statistical analysis was performed using two-way repeated ANOVA. Subsequent post hoc analysis was performed using Bonferroni's method. For all analyses, values of $\mathrm{p}<0.05$ were assumed to be significant $(\mathrm{n}=$ number of donors (tracheae) whose cultured epithelial cells were used).

\section{RESULTS}

\section{Effects of carbocisteine on rhinovirus infection in human tracheal epithelial cells}

Exposing confluent human tracheal epithelial cell monolayers to RV2 $\left(1 \times 10^{5} \mathrm{TCID} 50 \cdot \mathrm{mL}^{-1}\right)$ and RV14 $\left(1 \times 10^{5} \mathrm{TCID} 50 \cdot \mathrm{mL}^{-1}\right)$ consistently led to infection. No detectable virus was revealed $1 \mathrm{~h}$ after infection. RV2 and RV14 were detected in culture medium at $6 \mathrm{~h}$, and the viral content progressively increased during the period 6-24 h after infection (fig. 1a and c). Viral titres of supernatants collected 1-2 days after infection also contained significant levels of RV2 and RV14 (fig. 1a and c). Supernatant viral titres increased significantly with time for the first $48 \mathrm{~h}(\mathrm{p}<0.05$ using ANOVA).

Treatment of the cells with carbocisteine significantly decreased the titres of RV2 and RV14 in supernatants 24 and $48 \mathrm{~h}$ after infection (fig. 1a and c). Furthermore, carbocisteine
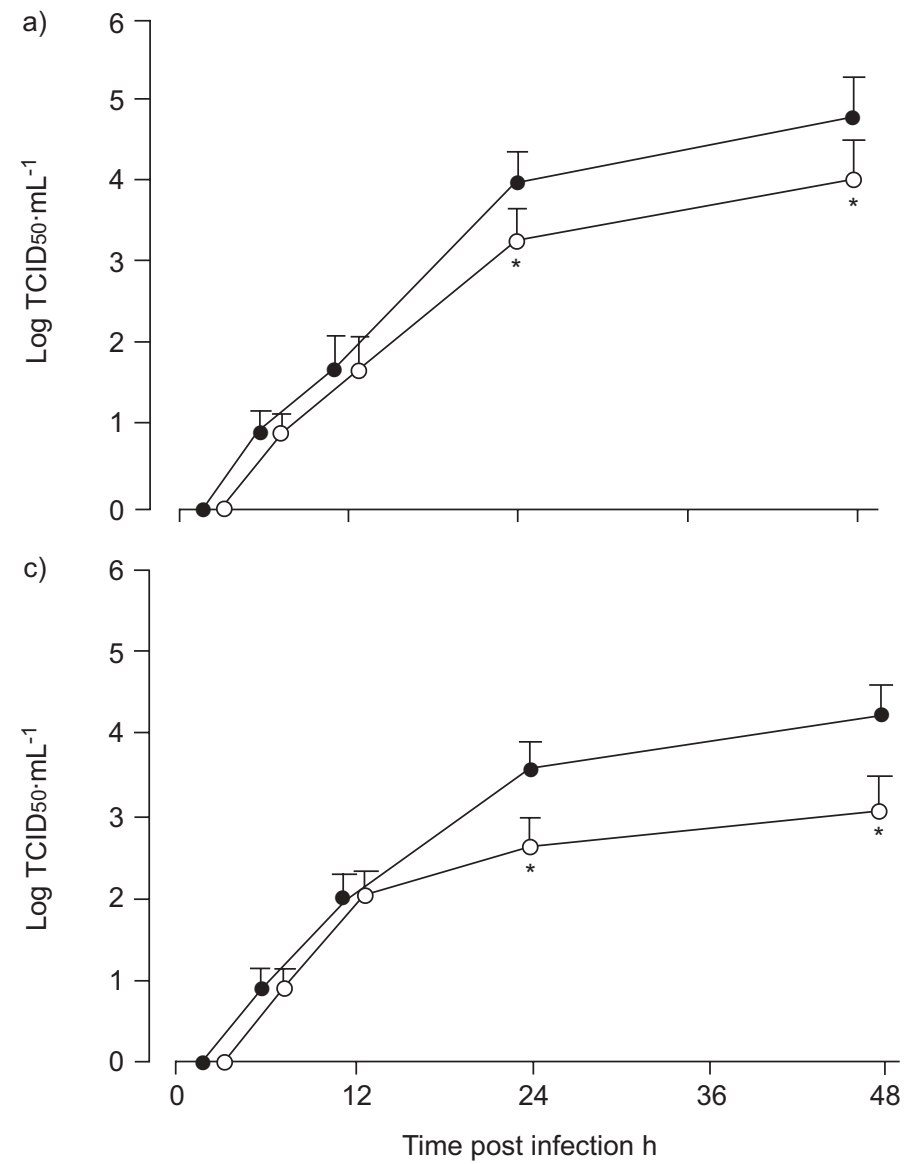

inhibited RV2 and RV14 infection in a concentration-dependent manner, the maximum effect being obtained at 10 and $30 \mu \mathrm{M}$ (fig. $1 \mathrm{~b}$ and $\mathrm{d}$ ).

In order to determine whether or not RV14 infection or carbocisteine-induced cytotoxic effects on the cultured cells caused cell detachment from the tubes after the cells had formed a confluent sheet, cell numbers were counted after RV14 infection and after treatment with carbocisteine. Cell numbers were constant in the confluent epithelial cells in the control medium, and the coefficient of variation was small $(7.3 \% ; \mathrm{n}=15)$. Neither RV14 infection $\left(1 \times 10^{5} \mathrm{TCID} 50 \cdot \mathrm{mL}^{-1}\right.$; 2 days) nor carbocisteine treatment $(10 \mu \mathrm{M} ; 5$ days $)$ had any effect on cell number (data not shown). Cell viability, assessed by trypan blue exclusion [7], was consistently $>96 \%$ in the carbocisteine-treated culture. RV14 infection and carbocisteine treatment $(10 \mu \mathrm{M})$ did not alter the amount of $\mathrm{LDH}$ in the supernatants. The amount of $\mathrm{LDH}$ in the supernatants was $29 \pm 2 \mathrm{IU} \cdot \mathrm{L}^{-1}$ before RV14 infection, $30 \pm 2 \mathrm{IU} \cdot \mathrm{L}^{-1} 2$ days after RV14 infection ( $p>0.50 ; n=5)$, and $30 \pm 2 \mathrm{IU} \cdot \mathrm{L}^{-1}$ after carbocisteine treatment $(10 \mu \mathrm{M} ; 5$ days $)(\mathrm{p}>0.50 ; \mathrm{n}=5)$.

\section{Effects of carbocisteine on viral RNA by PCR}

No detectable RV14 was revealed before RV14 infection (data not shown). RV14 was detected $24 \mathrm{~h}$ after RV14 infection

b)

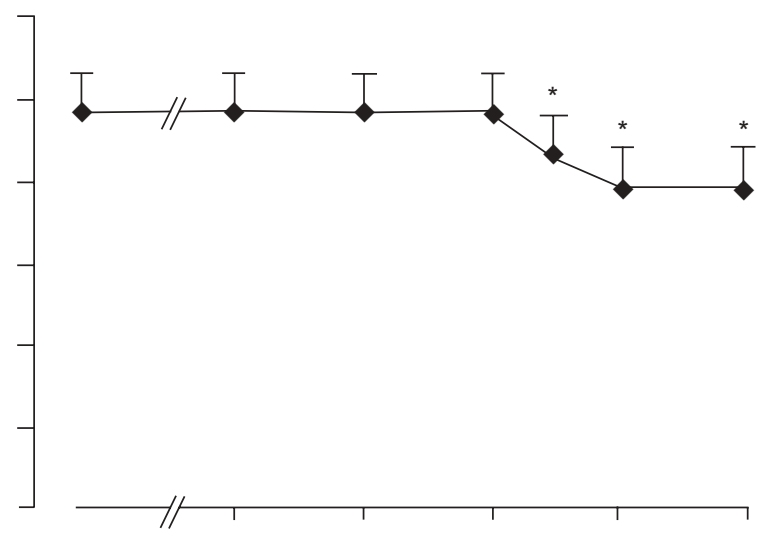

d)

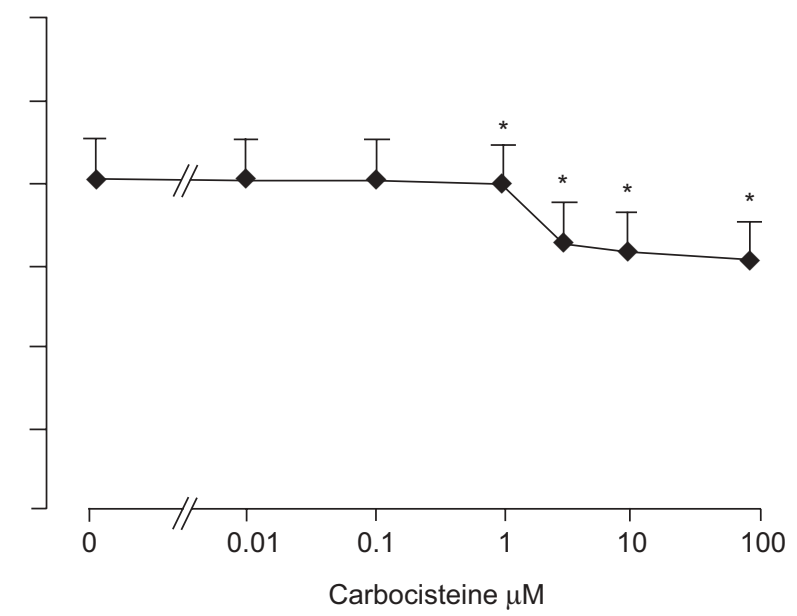

FIGURE 1. Viral titres (50\% tissue culture infective dose (TCID50) per millilitre) in supernatants of human tracheal epithelial cells obtained: a, c) at different times after exposure to $1 \times 10^{5} \mathrm{TCID} 50 \cdot \mathrm{mL}^{-1}$ rhinovirus (RV)14 (a) and RV2 (c) in the presence (O) of carbocisteine (10 $\mu \mathrm{M}$ ) or vehicle (PBS; $\bullet$ ); and b, d) at different concentrations of carbocisteine 24-48 h after infection with RV14 (b) and RV2 (d). The cells were treated with carbocisteine or vehicle beginning 3 days before RV14 infection and continuing the end of the experiments. Data are presented as mean \pm SEM $\left(n=5\right.$ tracheae). ${ }^{*}: p<0.05$ versus vehicle. 
(fig. 2a), and the amount of RV14 RNA in the cells was greater at $48 \mathrm{~h}$ than at $24 \mathrm{~h}$ (fig. $2 \mathrm{~b})$. Carbocisteine $(10 \mu \mathrm{M})$ caused a decrease in the amount of RV14 RNA in the cells 24 and $48 \mathrm{~h}$ after infection (fig. 2b). The magnitude of the inhibitory effects of carbocisteine $48 \mathrm{~h}$ after infection was greater than that $24 \mathrm{~h}$ (fig. 2b).

\section{Effects of carbocisteine on susceptibility to rhinovirus 14 infection}

Treatment of the cells with carbocisteine decreased their susceptibility to infection by RV14. The minimum dose of RV14 necessary to cause infection in cells treated with carbocisteine $\quad(10 \mu \mathrm{M} ; 3$ days $) \quad\left(2.6 \pm 0.2 \log \mathrm{TCID} 50 \cdot \mathrm{mL}^{-1}\right.$; $\mathrm{p}<0.05 ; \mathrm{n}=5$ ) was significantly higher than that in cells treated with vehicle (PBS) $\left(1.8 \pm 0.2 \log\right.$ TCID50 $\left.\cdot \mathrm{mL}^{-1} ; \mathrm{n}=5\right)$.
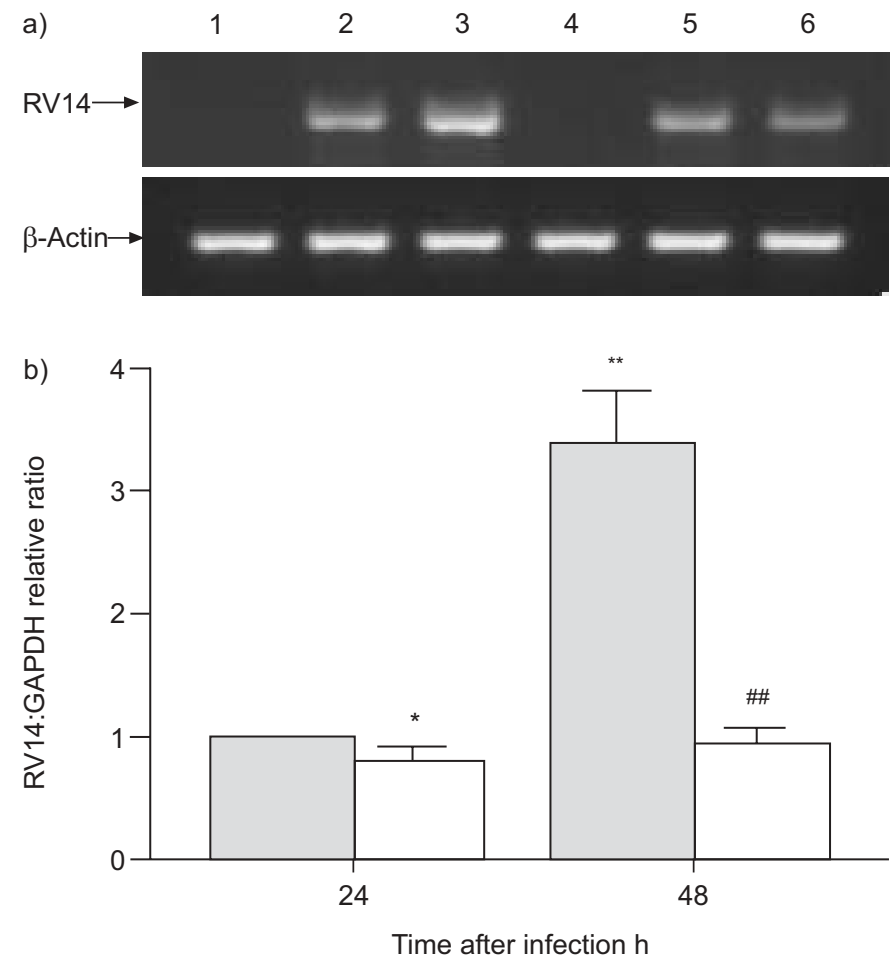

FIGURE 2. a) Replication of rhinovirus (RV) 14 RNA (381 bp) from human tracheal epithelial cells 0, 24 and 48 h (lanes 1-3 and 4-6, respectively) after RV14 infection in the presence of $10 \mu \mathrm{M}$ carbocisteine (lanes 4-6) or vehicle (PBS) alone (lanes 1-3) as detected by RT-PCR ( $\beta$-actin RNA 217 bp). Data are representative of three different experiments. b) Corresponding data obtained by real-time quantitative RT-PCR ( $\square$ : carbocisteine; $\square$ : vehicle). A standard curve was constructed using the fluorescence emission signals and the cycle threshold by means of 10 -fold dilutions of the total RNA, extracted from $1 \times 10^{5}$ of the $50 \%$ tissue culture infective dose (TCID50) $\mathrm{mL}^{-1} \mathrm{RV} 14$ in the supernatants of human embryonic fibroblasts 7 days after RV14 infection $\left(1 \times 10^{4} \mathrm{TCID} 50 \cdot \mathrm{mL}^{-1}\right)$. Real-time quantitative RT-PCR for reduced glyceraldehye-3-phosphate dehydrogenase (GAPDH) was also performed using the same PCR products. RV RNA expression was normalised to the constitutive expression of GAPDH mRNA and expressed relative to cells treated with vehicle alone $24 \mathrm{~h}$ after infection. Data are presented as mean \pm SEM $\left(n=5\right.$ tracheae). *: $p<0.05 ;{ }^{* *}: p<0.01$ versus vehicle 24 h after infection; ${ }^{\# \#}: p<0.01$ versus vehicle $48 \mathrm{~h}$ after infection.

\section{Effects of carbocisteine on expression of intercellular adhesion molecule-1}

Carbocisteine inhibited baseline ICAM-1 mRNA expression in the cells before RV14 infection (fig. 3a). Carbocisteine reduced ICAM-1 mRNA expression by $>50 \%$ compared with that of cells treated with vehicle (PBS) (fig. 3a). Likewise, carbocisteine significantly reduced supernatant sICAM-1 concentrations before RV14 infection (fig. 3b). In contrast, carbocisteine did not inhibit baseline LDL receptor mRNA expression in the cells before RV14 infection (fig. 3c).

\section{Effects of carbocisteine on cytokine production}

Carbocisteine reduced the baseline secretion of IL- 6 and IL- 8 for $24 \mathrm{~h}$ before RV14 infection compared with that in the cells treated with vehicle (PBS) (table 1). Furthermore, the secretion of IL-6 and IL-8 increased $24 \mathrm{~h}$ after RV14 infection. Carbocisteine also reduced the RV14 infection-induced secretion of IL- 6 and IL- 8 compared to that in the cells treated with vehicle $24 \mathrm{~h}$ after RV14 infection (table 1 ).

Conversely, carbocisteine inhibited the baseline secretion of IL$1 \beta$ for $24 \mathrm{~h}$ before RV14 infection compared with that in cells with no carbocisteine treatment (table 1). In contrast, the secretion of IL-1 $\beta 24 \mathrm{~h}$ after RV14 infection did not differ from that before RV14 infection (table 1). TNF- $\alpha$ was not detectable in supernatants for $24 \mathrm{~h}$ before and after RV14 infection.

Effects of carbocisteine on the acidification of endosomes Acidic endosomes in human tracheal epithelial cells were stained green using LysoSensor DND-189. Green fluorescence from acidic endosomes was observed in a granular pattern in the cytoplasm (data not shown), as previously described [7]. Carbocisteine decreased the number and fluorescence intensity

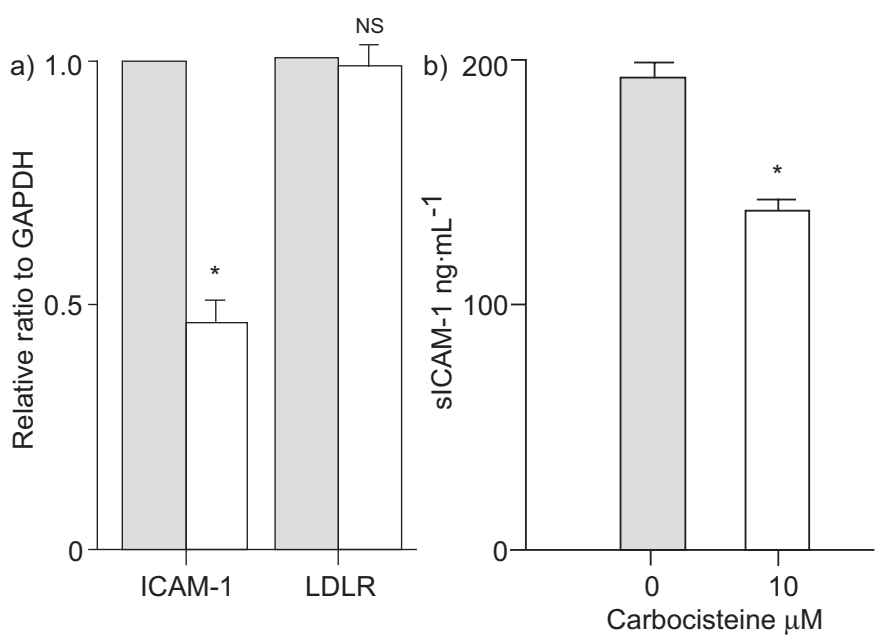

FIGURE 3. a) Expression of intercellular adhesion molecule (ICAM)-1 and lowdensity lipoprotein receptor (LDLR) mRNA in human tracheal epithelial cells 3 days after starting treatment with $10 \mu \mathrm{M}$ carbocisteine $(\square)$ or PBS vehicle $(\square)$ detected by real-time quantitative RT-PCR. mRNA expression was normalised to the constitutive expression of reduced glyceraldehyde-3-phosphate dehydrogenase (GAPDH) mRNA. b) Soluble ICAM (sICAM)-1 concentration in cell supernatants 3 days after starting treatment with $10 \mu \mathrm{M}$ carbocisteine or vehicle $(0 \mu \mathrm{M}$ carbocisteine). The medium was changed daily, and the supernatants collected $2-3$ days after starting treatment. Results are mean \pm SEM ( $n=5$ tracheae). NS: nonsignificant (versus control); *: $p<0.05$ versus control. 


\begin{tabular}{|c|c|c|c|c|}
\hline \multirow[t]{3}{*}{ TABLE 1} & \multicolumn{4}{|c|}{$\begin{array}{l}\text { Effects of carbocisteine on supernatant cytokine } \\
\text { contents before and } 24 \mathrm{~h} \text { after rhinovirus (RV) } 14 \\
\text { infection }\end{array}$} \\
\hline & \multicolumn{2}{|c|}{ Before infection } & \multicolumn{2}{|c|}{ After infection } \\
\hline & Control & Treated & Control & Treated \\
\hline $\mathrm{IL}-1 \beta \mathrm{pg} \cdot \mathrm{mL}^{-1}$ & $71 \pm 5$ & $40 \pm 3^{*}$ & $72 \pm 5$ & $39 \pm 3^{*}$ \\
\hline $\mathrm{IL}-6 \mathrm{pg} \cdot \mathrm{mL}^{-1}$ & $64 \pm 4$ & $36 \pm 3^{*}$ & $219 \pm 23^{*}$ & $123 \pm 15^{\star, \#}$ \\
\hline IL-8 pg $\cdot \mathrm{mL}^{-1}$ & $542 \pm 41$ & $517 \pm 37^{*}$ & $826 \pm 44^{*}$ & $491 \pm 58^{\star, \#}$ \\
\hline \multicolumn{5}{|c|}{$\begin{array}{l}\text { Data are presented as mean } \pm \text { SEM }(n=5 \text { for all). Human tracheal cells were } \\
\text { treated with either carbocisteine or PBS vehicle (control). }{ }^{*}: p<0.05 \text { versus } \\
\text { control before infection. }{ }^{\#:} p<0.05 \text { versus control } 24 \mathrm{~h} \text { after infection. IL: } \\
\text { interleukin. }\end{array}$} \\
\hline
\end{tabular}

of acidic endosomes with green fluorescence in the cells over time (fig. 4a). The fluorescence intensity of acidic endosomes in the epithelial cells treated with carbocisteine for $300 \mathrm{~s}$ was significantly reduced (fig. 4).

\section{Nuclear factor- $\kappa B$ DNA-binding activity in human tracheal epithelial cells}

Baseline nuclear factor (NF)- $\mathrm{B}$ DNA-binding activity was constant, and increased activation of NF- $\mathrm{B}$ DNA-binding activity was present in the cells 120 min after RV14 infection (fig. 5), as previously described [7]. Carbocisteine reduced the increased activation of NF- $\kappa \mathrm{B}$ occurring as a result of RV14 infection (fig. 5).

\section{DISCUSSION}

In the present study, it has been shown that a mucolytic drug, carbocisteine, reduced supernatant viral titres and viral RNA levels of a major group RV, RV14, in cultured human tracheal epithelial cells. Pretreatment with carbocisteine inhibited the expression of mRNA encoding ICAM-1, the receptor for the major group of RVs [14], as well as the supernatant concentrations of sICAM-1 before RV14 infection. Since the minimum dose of RV14 necessary to cause infection in cells treated with carbocisteine was significantly higher than that in cells treated with vehicle, carbocisteine may inhibit RV14 infection, at least partly, by reducing the production of its receptor, ICAM-1, as observed in human tracheal epithelial cells treated with dexamethasone [18] and erythromycin [7]. Furthermore, carbocisteine reduced the fluorescence intensity of acidic endosomes in the epithelial cells. The magnitude of the inhibitory effects of carbocisteine on the fluorescence intensity of acidic endosomes was similar to that of bafilomycin $A_{1}$ [17] and erythromycin [7]. Conversely, carbocisteine also reduced supernatant virus titres of a minor group RV, RV2, although it did not reduce the mRNA expression of the LDL receptor, the receptor for the minor group of RVs [24]. Carbocisteine may also inhibit RV2 and RV14 RNA entry across acidic endosomes, as demonstrated in HeLa cells and human tracheal epithelial cells treated with bafilomycin $A_{1}[16,17,26]$ and erythromycin [18].

Various viruses have been reported to be responsible for exacerbations of disease in patients with COPD and bronchial
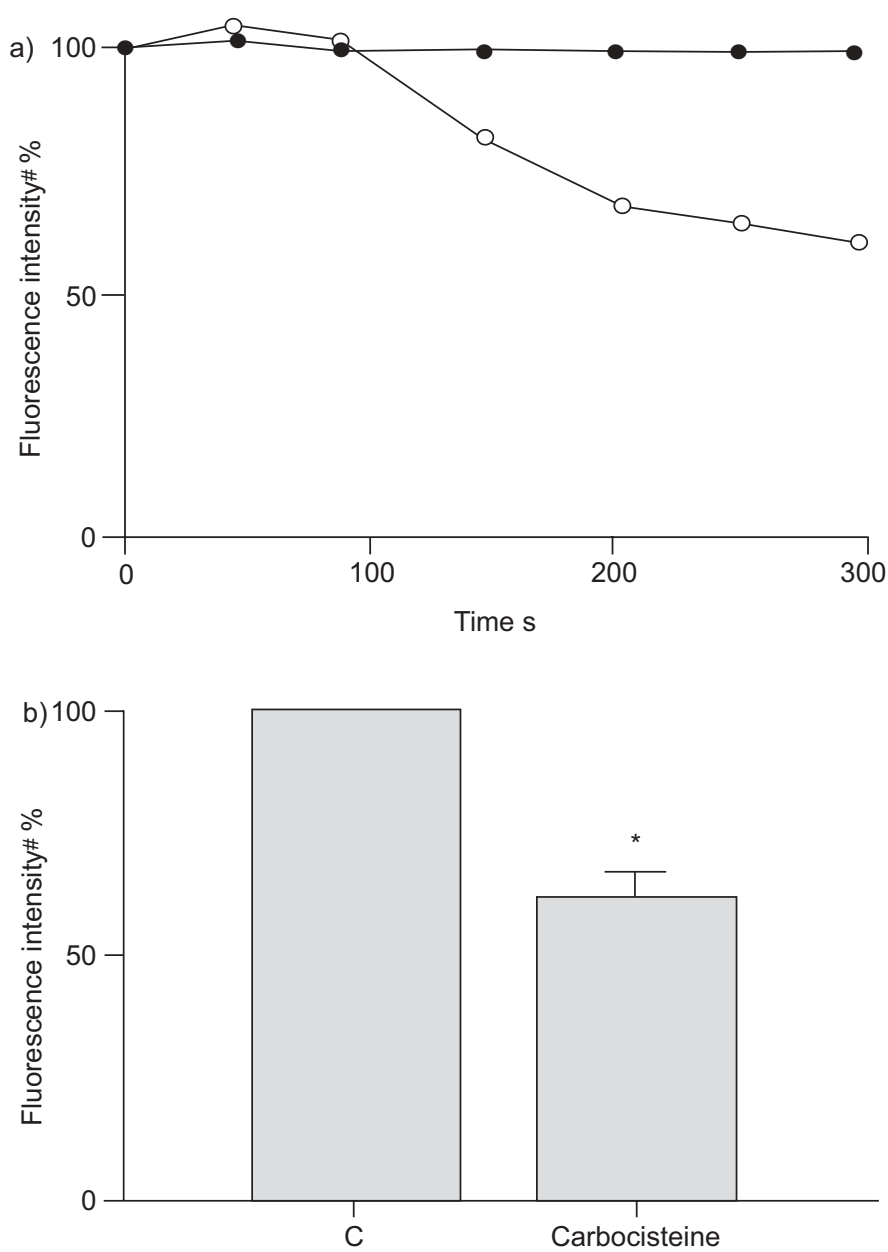

FIGURE 4. a) Time course of changes in the intensity of green fluorescence from acidic endosomes in human tracheal epithelial cells after treatment with either $10 \mu \mathrm{M}$ carbocisteine $(\bigcirc)$ or PBS vehicle $(\bullet)$. Inhibitors were administrated at time 0 . b) Fluorescence intensity of acidic endosomes $300 \mathrm{~s}$ after the addition of $10 \mu \mathrm{M}$ carbocisteine or vehicle (control (C)). The fluorescence intensity of acidic endosomes was measured in 100 human tracheal epithelial cells, and the mean expressed as a percentage of the control value $\left({ }^{\#}\right)$. Data are presented as mean \pm SEM $\left(n=5\right.$ tracheae). ${ }^{*}: p<0.05$ versus control.

asthma, including RVs, influenza virus and respiratory syncytial virus [2-4]. SEEMUNGAL et al. [3] reported that $64 \%$ of COPD exacerbations were associated with a cold before the onset of exacerbations; 77 viruses were detected in $39 \%$ of COPD exacerbations, and 39 (58\%) of these viruses were RVs. RVs are also associated with acute exacerbations in bronchial asthma [2]. These findings suggest that RVs may be a major pathogen responsible for acute exacerbations of COPD and bronchial asthma.

Various mechanisms have been attributed to the pathogenesis of COPD and bronchial asthma exacerbations, including airway inflammation, airway oedema, bronchoconstriction and mucus hypersecretion [4]. In addition, neutrophilic and eosinophilc inflammation in the exacerbations are associated with a variety of mediators, including IL- 6 and IL- 8 , and the production and secretion of IL- 6 and IL- 8 are stimulated by RV14 in airway epithelial cells, as shown in the present study as well as previous studies [5-7]. Furthermore, ICAM-1 


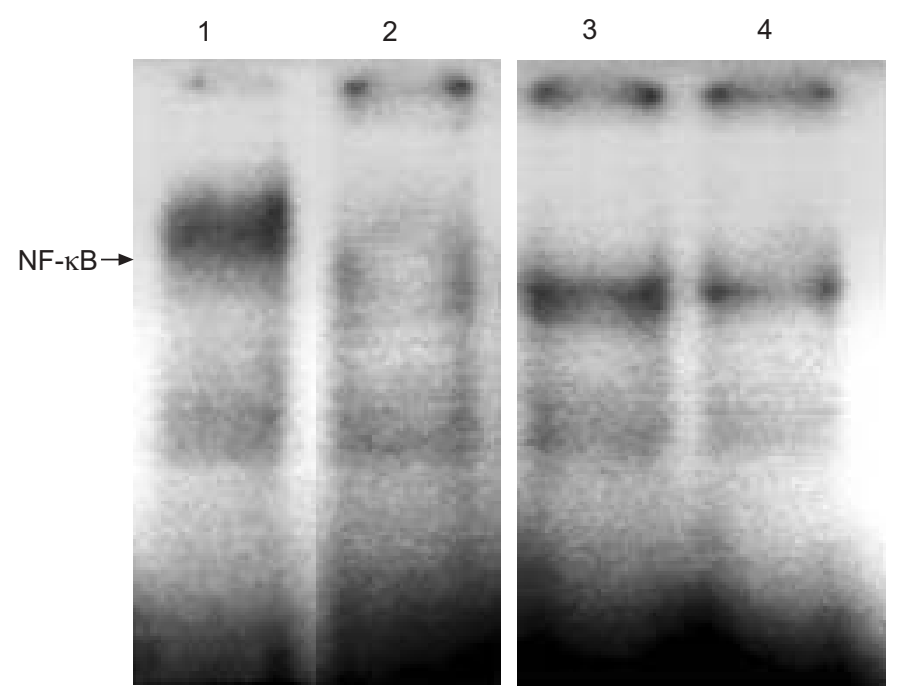

FIGURE 5. Nuclear factor (NF)-kB DNA-binding activity of human tracheal epithelial cells before (lane 2) and 120 min after (lanes 3 and 4) rhinovirus (RV) 14 infection in the presence of $10 \mu \mathrm{M}$ carbocisteine (lane 4) or PBS vehicle (lane 3) detected via electrophoretic mobility shift assay (lane 1: positive control $\left(10 \mathrm{ng} \cdot \mathrm{mL}^{-1}\right.$ $\mathrm{IL}-1 \beta$ plus $10 \mathrm{ng} \cdot \mathrm{mL}^{-1}$ tumour necrosis factor- $\alpha$ for $24 \mathrm{~h}$ )). The cells were treated with carbocisteine or vehicle from 3 days before until 120 min after RV14 infection. Data are representative of three different experiments.

interacts physiologically with leukocyte function-associated antigen-1, expressed on leukocytes, and thus plays a vital role in the recruitment and migration of immune effector cells to sites of local inflammation, as observed in patients with COPD [27]. Therefore, reduced RV14 infection-induced production of IL- 6 and IL- 8 by carbocisteine, observed in the present study, may be associated with the modulation of airway inflammation after RV infection, and with the prevention of acute exacerbations of chronic obstructive bronchitis, as previously described [9].

In the present study, carbocisteine reduced the baseline production of cytokines, including IL-1 $\beta$, IL-6 and IL-8, as well as ICAM-1, before RV14 infection. RV14 infection increased the production of IL- 6 and IL-8, and carbocisteine also reduced RV14 infection-induced production of IL-6 and IL-8. The concentration of IL-1 $\beta$ in supernatants had not changed $24 \mathrm{~h}$ after RV14 infection, and TNF- $\alpha$ was not detectable in supernatants $24 \mathrm{~h}$ after RV14 infection, as previously reported $[7,18]$. Since carbocisteine reduced the RV14 titre in supernatants, the inhibitory effects of carbocisteine on RV14 infection, and on cytokine production itself, might be associated with the reduced production of IL- 6 and IL- 8 in the cells treated with carbocisteine after RV14 infection.

Increased activation of NF- $\mathrm{B}$ was also apparent in cells 120 min after RV14 infection, as shown in previous studies [5, 7], and carbocisteine inhibited this activation. NF- $\mathrm{\kappa B}$ increases the expression of genes encoding many cytokines, such as IL-6, IL-8 and ICAM-1 [5]. Therefore, a reduction in cytokine and ICAM-1 levels might be mediated via the carbocisteinereduced activation of NF- $\mathrm{KB}$.

Endosomal $\mathrm{pH}$ is thought to be regulated by vacuolar $\mathrm{H}^{+}$ATPases [28] and ion transport across $\mathrm{Na}^{+} / \mathrm{H}^{+}$antiporters [28].
The inhibitors of $\mathrm{Na}^{+} / \mathrm{H}^{+}$antiporters, 5-(N-ethyl- $\mathrm{N}$-isopropy1)amiloride and $N^{\prime \prime}$-[5-hydroxymethyl-3-(1H-pyrrol-1-yl)benzoyl]guanidine methanesulphonate (FR168888), as well as a vacuolar $\mathrm{H}^{+}$-ATPase inhibitor, bafilomycin, increase endosomal $\mathrm{pH}$ and inhibit RV14 infection in cultured human tracheal epithelial cells [7]. Although there are no data to support this, the increased endosomal $\mathrm{pH}$ induced by carbocisteine in the present study may be associated with an inhibitory effect on vacuolar $\mathrm{H}^{+}$-ATPases or $\mathrm{Na}^{+} / \mathrm{H}^{+}$antiporters in airway epithelial cells.

Recent reports revealed that the major group of RVs enters the cytoplasm of infected cells after binding to its receptor, ICAM1 [14]. The entry of the RNA of a major group RV, RV14, into the cytoplasm of infected cells is thought to be mediated by destabilisation from receptor binding and endosomal acidification [15]. The inhibitory effects of carbocisteine on infection by RV14 and its effects on endosomal $\mathrm{pH}$ in the present study are consistent with those of bafilomycin and erythromycin in previous studies $[7,16,17]$. In addition, the inhibitory effects of carbocisteine on ICAM-1 expression in airway epithelial cells might also be associated with inhibitory effects on RV14 infection, as previously reported for the inhibitory effects of bafilomycin, erythromycin and dexamethasone [7, 17, 18].

In the present study, the inhibitory effects of carbocisteine were observed over a small range of concentrations, and there is no complete inhibition of infection. The precise reason for this is uncertain. However, the magnitude of the inhibitory effects of carbocisteine on supernatant RV titres was smaller than those of dexamethasone and erythromycin [7, 18]. The weak inhibitory effects of carbocisteine might show a small range of response and incomplete inhibition of infection. The magnitude of the inhibitory effects of carbocisteine on supernatant sICAM-1 concentrations was smaller than those of dexamethasone and erythromycin on ICAM-1 protein expression $[7,18]$, although the magnitude of the inhibitory effects of carbocisteine on the fluorescence intensity of acidic endosomes was similar to those of bafilomycin $A_{1}$ [17] and erythromycin [7]. Therefore, smaller inhibitory effects of carbocisteine on ICAM-1 expression might be partly associated with lesser inhibition by carbocisteine of RV infection compared with the inhibitory effects of dexamethasone and erythromycin.

Carbocysteine exerts an anti-oxidant action by scavenging reactive oxygen intermediates [29]. Indeed, SCMC-Lys reduces the concentration of 8-isoprostane, a prostaglandin-like compound, during peroxidation of membrane phospholipids by reactive oxygen species in the breath condensate of acute COPD patients [10]. Furthermore, bafilomycin $\mathrm{A}_{1}$, a blocker of vacuolar $\mathrm{H}^{+}$-ATPase, reduces endosome acidification [17] in airway epithelial cells and reduces production of reactive oxygen species in alveolar macrophages [30], suggesting a relationship between antioxidant effects and the reduced acidification of endosomes. Reduced production of inflammatory cytokines and ICAM- 1 by carbocisteine, in the present study, also suggests anti-inflammatory effects of carbocisteine, as shown in previous studies that demonstrated reduced IL-6 concentrations in breath condensate caused by SCMC-Lys in COPD patients [10] and reduced numbers of inflammatory cells in airways in rats caused by SCMC-Lys [11] and SCMC [12]. 
In summary, this is the first report that a mucolytic drug, carbocisteine, inhibits infection by rhinovirus 14 and decreases the susceptibility of cultured human tracheal epithelial cells to rhinovirus 14 infection, probably through the inhibition of intercellular adhesion molecule-1 expression and endosomal acidification. Carbocisteine also inhibited rhinovirus 2 infection, probably through the inhibition of endosomal acidification. Carbocisteine reduced baseline and rhinovirus infectioninduced release of pro-inflammatory cytokines, such as interleukin- 6 and -8 , in supernatants. Carbocisteine may inhibit infection by the major and minor group of rhinoviruses, and modulate inflammatory responses in the airway epithelial cells after rhinovirus infection.

\section{ACKNOWLEDGEMENTS}

The authors would like to thank G. Crittenden for reading the manuscript.

\section{REFERENCES}

1 Stanway G. Rhinoviruses. In: Webster RG, Granoff A, eds. Encyclopedia of Virology. Vol 3. London, Academic Press, 1994; pp. 1253-1259.

2 Nicholson KG, Kent J, Ireland DC. Respiratory viruses and exacerbations of asthma in adults. BMJ 1993; 307: 982-986.

3 Seemungal T, Harper-Owen R, Brownmik A, et al. Respiratory viruses, symptoms, and inflammatory markers in acute exacerbations and stable chronic obstructive pulmonary disease. Am J Respir Crit Care Med 2001; 164: 1618-1623.

4 Sethi S. New developments in the pathogenesis of acute exacerbations of chronic obstructive pulmonary disease. Curr Opin Infect Dis 2004; 17: 113-119.

5 Zhu Z, Tang W, Ray A, et al. Rhinovirus stimulation of interleukin-6 in vivo and in vitro. Evidence for nuclear factor $\kappa \mathrm{B}$-dependent transcriptional activation. J Clin Invest 1996; 97: 421-430.

6 Subauste MC, Jacoby DB, Richards SM, Proud D. Infection of a human respiratory epithelial cell line with rhinovirus. Induction of cytokine release and modulation of susceptibility to infection by cytokine exposure. J Clin Invest 1995; 96: 549-557.

7 Suzuki T, Yamaya M, Sekizawa K, et al. Erythromycin inhibits rhinovirus infection in cultured human tracheal epithelial cells. Am J Respir Crit Care Med 2002; 165: 1113-1118.

8 Akira S, Hirano T, Taga T, Kishimoto T. Biology of multifunctional cytokines: IL 6 and related molecules (IL 1 and TNF). FASEB J 1990; 4: 2860-2867.

9 Allegra L, Cordaro CI, Grassi C. Prevention of acute exacerbations of chronic obstructive bronchitis with carbocysteine lysine salt monohydrate: a multicenter, double-blind, placebo-controlled trial. Respiration 1996; 63: 174-180.

10 Carpagnano GE, Resta O, Foschino-Barbaro MP, et al. Exhaled interleukin-6 and 8-isoprostane in chronic obstructive pulmonary disease: effect of carbocysteine lysine salt monohydrate (SCMC-Lys). Eur I Pharmacol 2004; 505: 169-175.

11 Asti C, Melillo G, Caselli GF, et al. Effectiveness of carbocysteine lysine salt monohydrate on models of airway inflammation and hyperresponsiveness. Pharmacol Res 1995; 31: 387-392.

12 Sueyoshi S, Miyata Y, Masumoto Y, et al. Reduced airway inflammation and remodeling in parallel with mucin 5AC protein expression decreased by $S$-carboxymethylcysteine, a mucoregulant, in the airways of rats exposed to sulfur dioxide. Int Arch Allergy Immunol 2004; 134: 273-280.

13 Ishii Y, Kimura T, Morishima Y, et al. S-carboxymethylcysteine inhibits neutrophil activation mediated by $\mathrm{N}$ formyl-methyl-leucyl-phenylalanine. Eur J Pharmacol 2002; 449: 183-189.

14 Greve JM, Davis G, Meyer AM, et al. The major human rhinovirus receptor is ICAM-1. Cell 1989; 56: 839-847.

15 Casasnovas JM, Springer TA. Pathway of rhinovirus disruption by soluble intercellular adhesion molecule 1 (ICAM-1): an intermediate in which ICAM-1 is bound and RNA is released. J Virol 1994; 68: 5882-5889.

16 Pérez L, Carrasco L. Entry of poliovirus into cells does not require a low-pH step. J Virol 1993; 67: 4543-4548.

17 Suzuki T, Yamaya M, Sekizawa $\mathrm{K}$, et al. Bafilomycin $\mathrm{A}_{1}$ inhibits rhinovirus infection in human airway epithelium: effects on endosome and ICAM-1. Am J Physiol 2001; 280: L1115-L1127.

18 Suzuki T, Yamaya M, Sekizawa K, et al. Effects of dexamethasone on rhinovirus infection in cultured human tracheal epithelial cells. Am J Physiol 2000; 278: L560-L571.

19 Blesa S, Cortijo J, Mata M, et al. Oral N-acetylcysteine attenuates the rat pulmonary inflammatory response to antigen. Eur Respir J 2003; 21: 394-400.

20 Martell M, Gomez J, Esteban JI, et al. High-throughput realtime reverse transcription-PCR quantitation of hepatitis C virus RNA. J Clin Microbiol 1999; 37: 327-332.

21 Holland PM, Abramson RD, Watson R, Gelfand DH. Detection of specific polymerase chain reaction product by utilizing the 5'-3' exonuclease activity of Thermus aquaticus DNA polymerase. Proc Natl Acad Sci USA 1991; 88: 7276-7280.

22 Heid CA, Stevens J, Livak KJ, Williams PM. Real time quantitative PCR. Genome Res 1996; 6: 986-994.

23 Amador E, Dorfman LE, Wacker EC. Serum lactic dehydrogenase activity: an analytical assessment of current assays. Clin Chem 1963; 9: 391-399.

24 Hofer F, Gruenberger M, Kowalski H, et al. Members of the low density lipoprotein receptor family mediate cell entry of a minor group common cold virus. Proc Natl Acad Sci USA 1994; 91: 1839-1842.

25 De Schutter JA, Van der Weken G, Van den Bossche W, de Moerloose P. Determination of $S$-carboxymethylcysteine in serum by reversed-phase ion-pair liquid chromatography with column switching following pre-column derivatization with o-phthalaldehyde. J Chromatogr A 1988; 428: 301-310.

26 Prchla E, Kuechler E, Blaas D, Fuchs R. Uncoating of human rhinovirus serotype 2 from late endosomes. J Virol 1994; 68: 3713-3723.

27 Riise GC, Larsson S, Lofdahl CG, Andersson BA. Circulating cell adhesion molecules in bronchial lavage and serum in COPD patients with chronic bronchitis. Eur Respir J 1994; 7: 1673-1677. 
28 Marshansky V, Vinay P. Proton gradient formation in early endosomes from proximal tubules. Biochem Biophys Acta 1996; 1284: 171-180.

29 Brandolini L, Allegretti M, Berdini V, et al. Carbocysteine lysine salt monohydrate (SCMC-LYS) is a selective scavenger of reactive oxygen intermediates (ROIs). Eur Cytokine Network 2003; 14: 20-26.

30 Bidani A, Reisner BS, Haque AK, et al. Bactericidal activity of alveolar macrophages is suppressed by V-ATPase inhibition. Lung 2000; 178: 91-104. 